\title{
FUTURE OF SIMULATION IN BIOTECHNOLOGY INDUSTRY
}

\author{
Prasad V Saraph \\ B64-R329 \\ 800 Dwight Way \\ Bayer HealthCare - Biological Products \\ Berkeley, CA, 94710-2428, USA
}

\begin{abstract}
In the $21^{\text {st }}$ century, the Biotechnology industry has the potential to inspire a number of management tools and theories, just as the Automobile industry did in the $20^{\text {th }}$ century. This paper explores the opportunities for simulation in Biotechnology over the next few years and provides structure for the panel discussion in Biotechnology and HealthCare track. We detail the structure for Biotechnology industry, review status and opportunities for simulation and present gap analysis of opportunities and tools available. The purpose of the panel discussion is to discuss the role for simulation community in Biotechnology industry over the next few years and identify key areas where simulation can add value.
\end{abstract}

\section{BACKGROUND}

Role of Biotechnology industry in 21st century is similar to the role played by Automobile industry in the 20th century (Womack, Jones, Roos, 1991). Automobile industry promoted and developed the science of management (Taylor, 1911). simulation tools and theory developed out of rigor of management science. simulation has been effective in analyzing various operational and strategic issues (quantitative as well as qualitative).

Subsequent novel industries like Computer and Semiconductor created new challenges for simulation and pushed the application boundaries farther than any practitioner had predicted. In this first decade of 21 st century, simulation based tools and techniques have become an integral part of the modern organization in established industries.

However, Biotechnology industry is in the developing stage in terms of its structure and basic technologies. simulation based tools are still a novelty in this industry (Saraph, 2001). Scarcity of simulation applications creates an enormous opportunity for simulation community in this rapidly growing industry.

\section{PANEL DISCUSSION OBJECTIVES}

- Review the structure of Biotechnology industry

- Review status of simulation in Biotechnology industry

- Explore opportunities for simulation

- Discuss the role for simulation practitioners in the industry over next few years

\section{INDUSTRY STRUCTURE}

There are three distinct parts of this industry, Drug Discovery and Development, Operations and Commercial. Once an era of the Big Pharma, small companies and university groups now dominate the discovery and research phase. Operations phase is still the arena for large and established firms Pharmaceuticals and Biotech. There is a slow but steady penetration from Generic manufacturers in this area as well. Commercial phase consists of Marketing, Sales, Distribution, Life Cycle Management and in/out-licensing opportunity exploration. Figure 1 illustrates generic industry structure and roles of these three parts.

\begin{tabular}{|c|c|c|c|c|}
\hline Key Process & DD\&D & OPS & Comm & \multirow{11}{*}{$\begin{array}{l}\text { Drug } \\
\text { Discovery and } \\
\text { Development }\end{array}$} \\
\hline Drug Discovery & $x$ & i) & & \\
\hline Product Development & $x$ & & $x$ & \\
\hline Process Development & $x$ & & & \\
\hline Bioanalytics Development & $\mathrm{x}$ & ----- & ----- & \\
\hline Formulation \& Drug Delivery Systems & $x$ & & & \\
\hline Toxicology & $x$ & & & \\
\hline Pre-clinical Production & & $-x_{--}$ & & \\
\hline Scale-up Evaluation & $x$ & $x$ & & \\
\hline Clinical Production (Small, Pilot, Commercial) & $----r$ & $\mathrm{x}$ & & \\
\hline Clinical Trials (Phase I-III) & $x$ & & & \\
\hline Licensing Activities & 1 & $x$ & $=--$ & \multirow[t]{6}{*}{ Operations } \\
\hline Process Transfer & $x$ & $x$ & & \\
\hline Commercial Scale-up & 1 & $x$ & & \\
\hline Market Development & $T$ & & $x$ & \\
\hline Commercial Production & & $x$ & & \\
\hline Distribution & & ו1 & $x$ & \\
\hline Marketing & & I & $\mathrm{x}$ & \multirow{4}{*}{ Commercial } \\
\hline Sales & & & $\mathrm{x}$ & \\
\hline In/Out-licensing Opportunity Exploration & $x$ & $\mathrm{x}$ & $\mathrm{x}$ & \\
\hline Life Cycle Management & & I & $x$ & \\
\hline
\end{tabular}

Figure 1: Biotechnology Industry Structure 


\section{STATUS OF SIMULATION}

Simulation tools have been deployed in Biotech industry across a large spectrum. There is sophisticated software to identify drug candidates, to analyze human genome for decease triggers, to simulate behaviors of drug molecules and human body response and to simulate the manufacturing process mass balance.

Recently, there have been efforts to utilize simulation in analyzing scheduling and operations capacity issues (Saraph, 2002; Petrides, 2002). However, there is a marked lack of specialized software to enable industry specific analysis and optimization.

Biotech industry is recognizing the value of simulation tools in its pursuit of cost-effective treatment for patients across the value chain, but the coordinated efforts are far and few in-betweens.

\section{OPPORTUNITIES FOR SIMULATION}

In order to set the stage for discussion on opportunities, we are using the industry structure as a guide. In each of the segments, we have tried to put together material that would start the discussion. Though we do not claim the contents to be comprehensive, the intended purpose for the panel discussion is well served.

\subsection{Drug Discovery and Development Phase}

The relatively new status of Biotech industry resulted in significant activity in Drug Discovery and Development phase. Various small groups (either in universities or as new start-ups) dominate the arena. The tools used also have matured over the past two decades. Information technology has created new disciplines like Bio Informatics. However, the simulation tools used by this phase are different from the ones used by other established industries. The focus of simulation in this phase is still on the specific technologies being evaluated/developed (e.g. Drug Molecule Binding, Behavior of Human Body under new drugs, Behavior of target cells etc.). The discovery phase can benefit significantly from simulation tools that address issues of efficiency and effectiveness of the discovery process (e.g. cycle time reduction, improving PTS), but so far the opportunities have not received adequate attention of simulation practitioners.

Development phase relates to the analysis and tests on the discovered drug and leads to Clinical trials. Successful management of development life cycle of drug candidates can create a competitive advantage. In this area, there are a few efforts directed towards project management, but application of simulation tools (especially what-if tools) has significant opportunity. simulation tools that would enable analysis of scale-up issues offer facility/equipment needs, analyze process behaviors over long term are some of the specific opportunities.

\subsection{Operations}

By far, this is the largest area of opportunities for simulation Tools. The basic advantage of the Operations area is its similarity with established industries like Process Industries, which enables application of familiar tools and theories. However, there are key differences that pose a challenge for simulation practitioners. Some of these differences are as follows:

- Regulatory Environment: Most of the Biotechnology drugs operate under heavily regulated environment of FDA, EMEA etc.

- Cleanliness Requirements: Similar to Semiconductor industry, but excursions have far reaching consequences for operations

- Quality Test Times: Many of the tests depend on growth of microbes and as such, take a long time

- Documentation Times: Low product characterization creates significant documentation requirements for the process and all documents need to be checked and reviewed before releasing the product to the market.

- Personnel Skills: Being a new industry, many processes are not de-skilled enough. Low availability of skilled personnel coupled with high demand create many challenges in deployment and hiring/retention of employees.

- Licensing Activities: Various changes to process, equipment, facilities and products need to be licensed before commercial usage. The outcome of licensing applications is variable and can cause significant disturbances in operations.

- Documentation Structure: This is a new area for simulation tools, but very critical for Biotech operations. Various types of documents need to be updated and changed as part of the business. How best to link these and how to estimate impact of individual changes is an intriguing arena.

\subsection{Commercial}

The Biotechnology markets can be categorized as mass markets, class markets and niche markets. Mass markets include drugs that treat generic diseases like Diabetes. Class markets include drugs that treat non-critical conditions like cosmetic enhancements. Niche markets (where most of the Biotech drugs exist as of now) cater to small and specific patient populations for very narrow indications.

The commercial phase across all three market segments has similarities with other industries. Regulated logistics (temperature controls, trail of custody), varying requirements across different regions and markets and new ways to connect with customers (e.g. through PDAs) create unique opportunities to minimize costs and maximize customer service. 
Life Cycle Management, though similar in concept with other industries, is influenced by patents and long development and approval cycles. Opportunities to optimize and simulate the business impact are not fully explored as of now.

\section{ROLE FOR SIMULATION PRACTITIONERS}

The Biotech industry is expecting very healthy growth in terms of revenues and employment over the next decade (TA/DOC Report, 2003; BIO Facts, 2004). Growing industry also brings multitude of opportunities for various tools, one of which is simulation.

Simulation practitioners have three key roles to play in this growth.

- Advocates: The unfamiliarity of simulation amongst the leadership of Biotechnology industry can be effectively addressed with simulation practitioners acting as advocates within their own organizations. Focus should be on showing utility of simulation through small examples and case studies from comparable industries/disciplines.

- Researchers: Though simulation theory has been around for quite some time, there is need to create the right problems, develop the approaches and provide theoretical justification for the proposed approaches in Biotech applications.

- End-users: As with any new discipline, the best way to establish and promote simulation is through action. simulation practitioners need to utilize simulation tools in their own organizations and show the impact on business performance.

\section{EXPECTED OUTCOME OF PANEL DISCUSSION}

The growing Biotech industry has multiple roles for simulation community. This panel discussion is expected to help the simulation community identify key areas of opportunity by creating a common understanding about addressing the simulation needs of different parts of the industry.

\section{REFERENCES}

Biotechnology Industry Organization, Biotechnology Industry Facts, <http://www.bio.org/speeches/ pubs/er/statistics.asp> [accessed September 13, 2004].

Petrides, D., A. Koulouris, C. Siletti, 2002. Throughput Analysis and Debottlenecking of Biomanufacturing Facilities: A Job for Process Simulators, BioPharm, August 2002.

Saraph P., 2001. Simulating Biotech Manufacturing Operations: Issues and Complexities, Proceedings of the $33^{\text {rd }}$ Winter Simulation Conference 2001, pp. 524 - 530.
Saraph P., 2002. Capacity Analysis of Multi-product, Multi-resource Biotech Facility using Discrete Event Simulation, Proceedings of $34^{\text {th }}$ Winter Simulation Conference 2002.

Taylor, F W. 1911. The Principles of Scientific Management. W. W. Norton \& Co., NY.

US Department of Commerce Technology Administration (TA/DOC), A Survey of Use of Biotechnology in US Industry, 2003, NY.

Womack J, D. Jones, D. Roos 1991. The Machine that Changed the World, HarperCollins, NY. 